2 Aguocha CM, Durum CB, Newton EC, Amado KU, Loose EO, Give MN. Determinants of gambling among male students in secondary schools in Imo State, Nigeria. J Subst Use 2018; 24: 199-205.

3 Oyebisi EO, Alao KA, Popoola BI. Gambling behaviour of university students in south-western Nigeria. IFE Psychologia 2012; 20(1).

4 NOIPolls. New poll reveals rising trend of gambling in Nigeria: betting and gambling in Nigeria (15 Aug). NOIPolls, 2017 (https://noi-polls.com/new-poll-reveals-rising-trend-of-gamblingin-nigeria).

5 Nigerian National Lottery Act 2005. National Lottery Trust Fund, 2005 (http://nltf.gov.ng/wp-content/uploads/2018/02/NationalLottery-Act.pdf).

6 Abdulbaqi SZ, Tejideen TO, Raji, KO, Ajisegbede AO. Gambling among residents of Ilorin Metropolis: a study of causative factors. Ilorin J Hum Resour Manage 2019; 3: 2.

7 Temitope BE, Oyekola A, Mary BA. Personality Traits and financial strain as determinants of gambling behaviour among youth in Nigeria: a case study of youths in Oyo State and Ekiti State. Am Int ] Soc Sci Res 2019: 4(1): 1-8.
8 Aguocha CM, Duru CB, Nwefoh EC, Ndukuba AC, Amadi KU, Olose EO. Attitudes towards and perception of gambling among secondary school students in a developing country. Int Gamb Stud 2019; 19: 532-44.

9 World Health Organization. The ICD-10 Classification of Mental and Behavioural Disorders. Research and Diagnostic Criteria. World Health Organization, 1993.

10 Adenugba A, Akhuetie R, Umeokoro I. The determinants and effects of gambling culture on youths in Nigeria: the case of the city of Ibadan. Afr J Soc Sci 2018; 8: 104-18.

11 National Research Council. Pathological Gambling: A Critical Review. National Academy Press, 1999.

12 Reilly C. The prevalence of disordered gambling behavio in the United States: three decades of evidence. In Gambling and the Public Health (Part 1) (ed National Center for Responsible Gambling): 3-11. NCRG, 2009 (http://www.ncrg.org/ sites/default/files/uploads/docs/monographs/ncrg_monograph_ vol3.pdf).

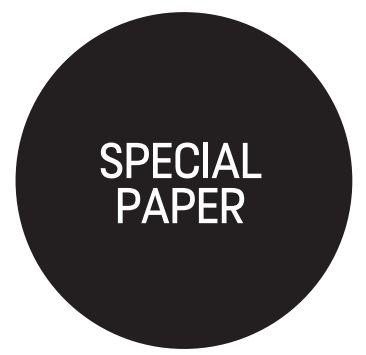

\title{
Gambling in Malaysia: an overview
}

\author{
Balan Rathakrishnan ${ }^{1}$ and Sanju George ${ }^{2}$ ๑
}

${ }^{1}$ Associate Professor, Faculty of Psychology and Education, Malaysia University of Sabah (UMS), Kota Kinabalu, Malaysia. Email: rbhalan@ums.edu.my

2Professor of Psychiatry and Psychology, Rajagiri School of Behavioural Sciences and Research, Rajagiri College of Social Sciences (Autonomous), Kochi, Kerala, India. Email: sanjugeorge531@gmail.com

Keywords. Gambling; law Malaysia; research.

First received 13 May 2020 Accepted 17 Sep 2020

doi:10.1192/bji.2020.55

Copyright () The Author(s), 2020 Published by Cambridge University Press on behalf of the Royal College of Psychiatrists. This is an Open Access article, distributed under the terms of the Creative Commons

Attribution licence (http://creative commons.org/licenses/by/4.0/), which permits unrestricted re-use, distribution, and reproduction in any medium, provided the original work is properly cited.

\section{Many forms of gambling are legal and popular in Malaysia. Despite this, in Malaysia, research into gambling is limited and there is no coherent strategy to tackle gambling-related harms. This paper summarises the gambling landscape of Malaysia, law governing gambling and research done so far and gives some recommendations on the way forward.}

Malaysia is a South East Asian country with a population of approximately 32.37 million people. Malaysia gained independence from the British Empire in 1963. Islam is the predominant religion $(61.3 \%)$, followed by Buddhism $(19.8 \%)$, Christianity $(9.2 \%)$ and Hinduism (6.3\%), and the rest practice traditional Chinese religions. ${ }^{1}$ Gambling is forbidden under Islamic law (Sharia law) so most Muslims do not engage in legal gambling. As Malaysia has a multi-ethnic population, with Malay making up 63\%, Chinese making up approximately $25 \%$ and those with Indian ancestry making up $12 \%$ of the total 32.37 million population, it is these latter groups who gamble more through legal means and who spend more on gambling. ${ }^{2,3}$

'Gambling disorder' sits alongside the more traditional substance addictions in DSM-5. In ICD-11, the ICD-10 term 'pathological gambling' is replaced by 'gambling disorder'.

\section{Gambling in Malaysia}

It would appear that gambling was 'brought' to Malaysia by Chinese merchants in the 19th century. Gambling, both legal and illegal forms, is very popular in Malaysia. ${ }^{4}$ Some forms of gambling, such as lotteries, casino games and horse racing, are legal in Malaysia, whereas all forms of sports betting (at bookmakers) and online gambling are illegal. Gambling is legal only if a license or permit has been granted by the authorities the Unit Kawalan Perjudian (Betting Control Unit) of the Ministry of Finance. Lotteries in Malaysia are allowed under the Lotteries Act 1952. Currently, there are six legal lotteries (all privately owned) in Malaysia). Alongside these, there exist several illegal lottery businesses and it was estimated that in 2018 'Malaysia's illegal lottery business generated about 60 percent more revenue than the six legal operators combined' ${ }^{5}$

There is only one legal land-based casino in Malaysia. This privately owned casino was set up in the 1970s in a very 'Las Vegas style' and is open $24 \mathrm{~h}$ a day but denies entry to Muslims and those under 21 years of age. This casino offers over 400 types of electronic table games, 3000 slot machines and 30 tables with games such as blackjack, tai sai, roulette and boule.

Horse racing was introduced in Malaysia by the British during the 1800s and currently there are three racecourses and betting on horses is 
legal. All three racecourses are privately owned and are regulated by the Racing Act $1961 .^{6}$

Despite being illegal, online gambling has been increasing in popularity over the past few years in Malaysia. Betting on badminton and football (mostly English football - the Premier League) is immensely popular. Technological advancements have made online gambling opportunities more accessible and more affordable. Although illegal, international betting sites accept customers from Malaysia and process deposits and withdrawals in ringgits ( $\mathrm{RM}$, the Malaysian currency).

\section{Gambling laws in Malaysia}

There are three major legal frameworks that dictate gambling laws in Malaysia: the Betting Act 1953, the Common Gaming Houses Act 1953 and Shariah law. The Betting Act 1953 (with several further amendments) is the most important of these. ${ }^{7}$ This Act bans all forms of gambling unless the company has a legal license to operate and covers telecommunications and other means of transmitting bets between customers and betting houses. As per this Act, anyone caught running a betting house or caught in one will be penalised with a RM200 000 fine and 5 years in jail.

The Common Gaming Houses Act 1953 (with further amendments) is more inclusive than the Betting Act in its coverage of types of gambling. ${ }^{7}$ The Common Gaming Houses Act defines gaming as: 'the playing of any game of chance or of mixed chance and skill for money or money's worth'. In the 2020 budget plan for Malaysia, the Finance Minister announced an increase in punishments for both illegal gamblers and gambling operators. The maximum penalty for those who gamble illegally was increased 20-fold, from RM5000 to RM100000, and a minimum jail sentence of 6 months was introduced.

Islam being the predominant religion, Malaysia also recognises Sharia law and Sharia (or Syariah) courts. Non-Malays (mostly ethnic Chinese and Indian) are not bound by Sharia law but by the secular legal system. All forms of gambling are forbidden under the Sharia law.

\section{Gambling research in Malaysia}

Gambling research in Malaysia has been limited.

Tan et $\mathrm{al}^{3}$ analysed data from 6117 nonMuslim households for sociodemographic determinants of gambling participation and gambling expenditure. They found that the sociodemographic factors associated with higher levels of gambling expenditure were being young, Chinese, having lower education levels and higher income, and being from paternal-headed families.

Two hundred patrons of the only casino in Malaysia were examined for their demographics, gambling behaviour and factors contributing to gambling decisions. ${ }^{9}$ It was found that marketing activities such as promotions, services, positioning and winnings predicted greater gambling behaviour, whereas psychological variables such as motivation, personality, perception and cognition did not.
Loo \& $\mathrm{Ang}^{10}$ studied the prevalence of problem gambling in Malaysia's largest state (Selangor, with a population of 5.6 million) and found that $4.4 \%$ of the general population were problem gamblers and $10.2 \%$ were moderate-risk gamblers.

Loft \& Loo $^{11}$ analysed sleep difficulty, sleep habits, arousability, self-regulatory capacity and problem-gambling severity in 59 treatmentseeking gamblers and noted that self-regulatory capacity mediated the relationship between problem gambling and sleep difficulty, and that it was a significant mediator between problem gambling and negative sleep habits.

In a more recent study, Sheela et $\mathrm{al}^{12}$ looked at 2265 Malaysian adolescents and found that around $30 \%$ of them participated in some form of gambling over a 12-month period. They also noted that parental gambling, being male and high-risk behaviours were associated closely with adolescent gambling.

\section{Treatment services for gamblers in Malaysia}

There are no structured gambling treatment facilities in the public sector in Malaysia. Several private rehabilitation centres offer residential and outpatient help for problem gamblers. There are no offline Gamblers Anonymous (GA) meetings in Malaysia but online access to GA is possible. We are aware that private psychiatric hospitals and addiction specialists offer individual psychotherapies (mostly cognitive-behavioural therapy) for problem gamblers and supportive psychotherapy to their families.

Anecdotes suggest that most people with gambling-related problems go unrecognised and untreated. Problems often only come to light when they are severe or when the gambler comes to the attention of the legal system for gambling-related debt, bankruptcy, financial fraud, domestic violence and other crimes.

\section{The way forward}

The issue of gambling in an Islamic country like Malaysia is fraught with difficulties, unlike in more secular countries. This is because of Malaysia's unique dual system of law - the Sharia-governed Syariah courts for the nation's Muslims (over half of the total population), which strongly oppose gambling, and secular law that is less rigid in its take on gambling.

First, there needs to be a wider debate on whether gambling ought to be banned altogether in Malaysia or whether it can be liberalised (at least in certain forms) and tightly regulated. Such a debate needs to involve multiple stake holders, including policy makers, academics, healthcare professionals and the gambling industry. At the very least, existing legislation needs to be updated to include online gambling in its various guises. Second, more needs to be done to minimise gambling-related harm and it might be best to start with public health approaches such as awareness-raising campaigns about various aspects of gambling, its potential for harm, signs 
and symptoms, how to seek help, banning and enforcement thereof of gambling advertisements and promotions (in both print and online media) and the increasing in-counter-advertising whereby this type of advertisement focuses on certain issues, persons or products to take a stand against other adverstisements in regards to controversial topics. Third, treatment services for Malaysia's problem gamblers and their families need to be expanded into the public sector as well. Given that gambling is illegal and banned under Sharia law in Malaysia, it is best viewed as a mental health problem with adverse public health impact. Healthcare service providers and health policy makers need to work together to provide psychological and psychiatric treatments in the community and hospital settings. This should include rehabilitation centres for those addicted. Fourth, more research needs to be done into the prevalence of problem gambling and gamblingrelated harms. Finally, we believe that developing a national gambling strategy and having an independent body to oversee it will aid the translation of the above suggestions into reality.

\section{Author contributions}

B.R. contributed to the gathering of information on gambling issues in Malaysia, both legal and illegal, and how people's perception of gambling has changed in Malaysia. S.G. contributed to the overall idea and structure of this manuscript. He provided the element on the treatment of gambling and addicted behavior.

\section{Declaration of interests}

None.

ICMJE forms are in the supplementary material, available online at https://doi.org/10.1192/bji. 2020.55 .

\section{References}

1 Department of Statistics Malaysia. Population Distribution and Basic Demographic Characteristic Report 2010 (Updated: 05/08/ 2011). Department of Statistics Malaysia, 2010.

2 Tan AKG, Yen ST, Nayga RM Jr. The demand for vices in Malaysia: an ethnic comparison using household expenditure data. Atl Econ J 2009; 37: 367-82.

3 Tan AKG, Yen ST, Nayga RM Jr. Socio-demographic determinants of gambling participation and expenditures: evidence from Malaysia. Int J Cons Stud 2010; 34: 316-25.

4 Loo JMY, Phua KL. Gambling participation and policies in Malaysia. Asian J Gambl Issues Public Health 2016; 6(1): 3.

5 Singleton S. Malaysia illegal lottery revenue tops legal operators. Asia Gaming Briefs 2019; 21 Mar.

6 Commissioner of Law Revision, Malaysia. The Racing (Totalizator Board) Act 1961 (Revised 1992). Commissioner of Law Revision, Malaysia, 1992 (http://www.commonlii.org/my/ legis/consol_act/rba19611992323/).

7 Commissioner of Law Revision, Malaysia. Laws of Malaysia Reprint Act 495 Betting Act 1953 (Incorporating all Amendments up to 1 January 2006). Commissioner of Law Revision, Malaysia, 2006 (http://www.agc.gov.my/agcportal/ uploads/files/Publications/LOM/EN/Act\%20495.pdf).

8 Narayan N. Malaysian Budget Increases Gambling Penalties (Press Release). European Gaming, 2019; 17 Oct.

9 Tudin R, Woon CY. Factors Influencing Individuals' Gambling Behaviour: A Case Study in Malaysia (FEB Working Paper Series no. 1202). Faculty of Economics and Business, Universiti Malaysia Sarawak, 2012

10 Loo JMY, Ang KT. Prevalence of Problem Gambling in Selango Urban Areas. Monash University Malaysia/Malaysian Mental Health Association, 2013.

11 Loft MH, Loo JMY. Understanding the mechanisms underlying gambling behaviour and sleep. J Gambl Stud 2014; 31: 1273-86.

12 Sheela PS, Choo WY, Goh LY, Tan CPL. Evidence from a school-based survey in the Malaysian setting. J Gambl Stud 2016; 32: 643-59.

\title{
SPECIAL
}

International experience of hikikomori PAPER (prolonged social withdrawal) and its
relevance to psychiatric research

\author{
Marcus P. J. Tan, ${ }^{1} \odot$ William Lee ${ }^{2}$ and Takahiro A. Kato ${ }^{3}$
}

ST5 Trainee in Child and Adolescent Psychiatry, South London and Maudsley NHS Foundation Trust, UK. EHS MPJTan@doctors.org.uk ${ }^{2}$ Consultant Liaison Psychiatrist, Devon Partnership NHS Trust, Exeter, UK

${ }^{3}$ Associate Professor, Department of Neuropsychiatry, Graduate School of Medical Sciences, Kyushu University, Japan
When prolonged social withdrawal was first described in Japan as 'hikikomori', many studies examining its etiology suggested it to be related to factors unique to Japan and thus a culture-bound syndrome. However, existing research has suffered from a lack of standardised definitions, impeding comparability between studies. We summarise existing research and discuss its relevance to psychiatric practice today.

\section{What is hikikomori?}

In Japan, there exists the term 'hikikomori', used to refer to a particularly severe form of social withdrawal. The term is part of the everyday lexicon in the Japanese language, where it is a compound verb made up of the two characters for 'to pull back' (hiku) and 'to seclude oneself' (komoru), and is used to describe a person's deliberate seclusion of themselves from mainstream society. ${ }^{1}$ The term was introduced to the medical community by the Japanese psychiatrist Tamaki 